\title{
Prevalence and clinical features of most frequent phenotypes in the Italian COPD population: the CLIMA Study
}

\author{
Roberto W. Dal Negro, ${ }^{1}$ Mauro Carone, ${ }^{2}$ Giuseppina Cuttitta, ${ }^{3}$ Luca Gallelli, ${ }^{4}$ Massimo Pistolesi, ${ }^{5}$ \\ Salvatore Privitera, ${ }^{6}$ Piero Ceriana, ${ }^{7}$ Pietro Pirina, ${ }^{8}$ Bruno Balbi, ${ }^{9}$ Carlo Vancheri, ${ }^{10}$ Franca M. Gallo, ${ }^{11}$ \\ Alfredo Chetta, ${ }^{12}$ Paola Turco, ${ }^{13}$ on behalf of the CLIMA Study Group* \\ ${ }^{I}$ National Center for Respiratory Pharmacoeconomics and Pharmacoepidemiology, Verona; ${ }^{2}$ ICS Maugeri IRCCS, Cassano \\ delle Murge (BA); ${ }^{3}$ Institute of Biomedicine and Molecular Immunology, National Research Council, Palermo; \\ ${ }^{4}$ Pharmacology Operative Unit, University Hospital Authority "Mater Domini”, Catanzaro; ${ }^{5}$ Pneumologia e Fisiopatologia \\ Toraco-Polmonare, Azienda Ospedaliera Universitaria Careggi, Firenze; ${ }^{6}$ C.P.M., Giarre (CT); ${ }^{7}$ Occupational Health and \\ Rehabilitation Clinic, ICS Maugeri IRCCS, Pavia; ${ }^{8}$ Pneumology Operative Unit, University Hospital Authority, Sassari; \\ ${ }^{9}$ Pneumology Rehabilitation Unit, ICS Maugeri IRCCS, Veruno (NO); ${ }^{10}$ Pneumology Rehabilitation Unit, University Hospital \\ Authority, Policlinico Vittorio Emanuele, Catania; ${ }^{11}$ Departmental Structure for Territorial Pneumology, Local Health \\ Authority, Matera; ${ }^{12}$ Pneumology Clinic, University Hospital Authority, Hospital “G. Rasori”, Parma; ${ }^{13}$ Research and Clinical \\ Governance, Verona, Italy
}

\begin{abstract}
Background: Chronic obstructive pulmonary disease (COPD) is a complex, progressive respiratory condition characterized by heterogeneous clinical presentations (phenotypes). The aim of this study was to assess the prevalence of the main COPD phenotypes and match of each phenotype to the most fitting clinical and lung function profile.

Methods: the CLIMA (Clinical Phenotypes in Actual Clinical Practice) study was an observational, cross-sectional investigation involving twenty-four sites evenly distributed throughout Italy. Patients were tentatively grouped based on their history and claimed prevailing symptoms at recruitment: chronic cough (CB, suggesting chronic bronchitis); dyspnoea (possible emphysema components, E); recurrent wheezing (presuming asthma components, A). Variables collected were: anagraphics; smoking habit; history of asthma; claim of $>1$ exacerbations in the previous year; blood eosinophil count; total blood IgE and alpha $_{1}$ anti-trypsin $\left(\alpha_{1}\right.$-AT) levels; complete lung function, and the chest X-ray report. mMRC, CAT, BCS, EQ5d-5L were also used. The association between variables and phenotypes were checked by Chi-square test and multinomial logistic regression.

Results: The CB phenotype was prevalent (48.3\%), followed by the E and the A phenotypes $(38.8 \%$ and $12.8 \%$, respectively). When dyspnoea was the prevailing symptom, the probability of belonging to the COPD-E phenotype was 3.40 times higher. Recurrent wheezing was mostly related to the COPD-A phenotype. Lung function proved more preserved in the COPD-CB phenotype. Smoke; $n$. exacerbations/year; VR, and BODE index were positively correlated with the COPD-E phenotype, while $\mathrm{SpO}_{2}, \mathrm{FEV}_{1} / \mathrm{FVC}, \mathrm{FEV}_{1} / \mathrm{VC}$, and $\mathrm{FEV}_{1}$ reversibility were negatively correlated. Lower DLco values were highly probative for the COPD-E phenotype $(\mathrm{p}<0.001)$. Conversely, smoke, wheezing, plasma eosinophils, FEV ${ }_{1}$ reversibility, and DLco were positively correlated with the COPD-A phenotype. The probability of belonging to the COPD-A phenotype raised by 2.71 times for any increase of one unit in \% plasma eosinophils $(\mathrm{p}<0.001)$. Also multiparametrical scores contributed to discriminate the three phenotypes.

Conclusion: The recognition of the main phenotypes of COPD can be effectively pursued by means of a few clinical and instrumental parameters, easy to obtain also in current daily practice. The phenotypical approach is crucial in the management of COPD as it allows to individualize the therapeutic strategy and to obtain more effective clinical outcomes.
\end{abstract}

Key words: COPD; COPD phenotypes; clinical pictures; chronic bronchitis; emphysema, bronchial asthma, airway disease.

Correspondence: Roberto W. Dal Negro, National Center for Respiratory Pharmacoeconomics and Pharmacoepidemiology, via G. Rossetti 4, 37124 Verona, Italy. E-mail: robertodalnegro@gmail.com

Contributions: RWDN, PT, planned the study and wrote the manuscript; PT, provided critical feedback and contributed to the final version of the manuscript. All other Authors contributed to the patients' recruitment. All the authors have read and approved the final version of the manuscript and agreed to be accountable for all aspects of the work.

Conflict of interest: Authors declare no conflict of interest in the present investigation. RWD is Associate Editor of Multidisciplinary Respiratory Medicine.

Availability of data and materials: The datasets used and/or analyzed during the current study are available from the corresponding author on reasonable request.

Ethics approval and consent to participate: The study was approved by the Ethical Committee of Perugia during the session of 2017 , June $15^{\text {th }}$. All subjects gave their informed consent to the anonymous use of their own data for research purposes.

Consent for publication: All subjects gave their informed consent. 


\section{Introduction}

Chronic obstructive pulmonary disease (COPD) is known since long ago as a pathological condition characterized by significant progression and by a huge epidemiological and socio-economic impact worldwide [1-3], Italy included [4].

The exact identification of COPD is not usually pursued in real world clinical practice. Actually, the main crucial aspect which mostly affects the clinical recognition and the appropriate management of COPD is the heterogeneity of pathogenetic mechanisms underlying the current airflow limitation, in many cases variably mixed [5-7]. Currently, at least three main groups of pathogenetic determinants underlie to COPD, ranging from those that predominantly characterize chronic bronchitis to those variably related to emphysema, or those mimicking bronchial asthma: unfortunately, they usually are all included in the same comprehensive term "COPD" [8-15].

Such a pathogenetic heterogeneity entails different clinical presentations of COPD that further contribute to increase the diagnostic uncertainty [16-18]. In the literature, the consolidated definition used for these various presentations of COPD is "clinical phenotypes of COPD" [19-21], even if their exact definition is still not consensual [22-24].

To our best knowledge, the effective prevalence of main phenotypes of COPD had never been investigated in Italy by dedicated studies conducted in real-life on representative samples of patients. The aim of the present study was to assess the prevalence of the main phenotypes of COPD in Italy, and to correlate each phenotype to the most fitting clinical and lung function profile.

\section{Methods}

The CLIMA (Clinical Phenotypes in Actual Clinical Practice) study was an observational, cross-sectional investigation. The study involved twenty-four pneumological sites evenly distributed throughout Italy. The study consisted of a single visit at the referring site. During the visit, the anagraphics, the clinical history, some biological data, and lung function were collected as per normal clinical practice.

Inclusion criteria were: i) COPD patients of both genders, aged $\geq 40$ years, with airway flow limitation (post-bronchodilator $\mathrm{FEV}_{1}$ / FVC ratio < 0.7) in stable clinical condition; ii) subjects who provided their informed consent. Exclusion criteria were: i) patients who did not meet the inclusion criteria; ii) patients who refused their informed consent; iii) subjects with severe cognitive and/or physical limitations that could interfere with the protocol procedures or make impossible any collection of anamnestic data or instrumental procedures.

Stemming from very simple clinical criteria currently used in daily practice, three clusters of patients with chronic airway obstruction were tentatively identified, independently of any comorbidity:

a. patients with chronic productive chronic cough as their prevailing symptom, such as a condition suggesting Chronic Bronchitis as the predominant disorder (COPD-CB phenotype);

b. patients with dyspnoea as their prevailing symptom, in the absence of any history of bronchial asthma: a condition that might suggest the existence of some emphysema components in COPD (COPD-E phenotype);

c. patients with recurrent wheezing as their prevailing symptom: a condition that might suggest the presence of some asthma components in COPD (COPD-A phenotype).
As the study was designed per normal clinical practice and the CT was not available in the great majority of patients, the concomitant presence of bronchiectasis was not considered as a phenotype to investigate in the present study.

Variables to collect were: age; gender, BMI; smoking habit; history of asthma and/or allergy; claim of $>1$ exacerbations in the previous 12 months; degree of dyspnoea; recurrence of wheezing; blood eosinophil count $>3 \%$ and $\geq$ cells $/ \mu \mathrm{L}$; total blood $\mathrm{IgE}$ and alpha $_{1}$ anti-trypsin $\left(\alpha_{1}-\mathrm{AT}\right)$ levels $<100 \mathrm{mg} / \mathrm{dl}$. Lung function data to collect were: $\mathrm{FEV}_{1}, \mathrm{FVC}$, and $\mathrm{VC} \%$ predicted; $\mathrm{FEV}_{1} / \mathrm{FVC}$ and $\mathrm{FEV}_{1} / \mathrm{VC}$ ratio; $\mathrm{RV} \%$ predicted; \% short-term $\mathrm{FEV}_{1}$ reversibility from baseline $\left(\mathrm{FEV}_{1}\right.$ increase $\geq 12 \%$ and $200 \mathrm{ml} 30$ ' after salbutamol $400 \mathrm{mcg}$ ); DLco \% predicted; $\mathrm{SpO}_{2}$, and BODE Index. The description of the chest $\mathrm{x}$-ray was also recorded, paying attention to the clear mention of "emphysema" in the radiological report. When already available, biological, radiological and lung function data should not be older than 6 months prior to the visit.

The following questionnaires were also administered to patients: - the Modified Questionnaire of British Medical Research

Council (mMRC), in order to associate the degree of dyspnea with the level of physical exercise;

- the COPD Assessment Test (CAT): aimed to assess the impact of COPD on patients' quality of life;

- the Borg Category Scale (BCS ): to assess symptoms of breathlessness;

- the Quality-of-Life Questionnaire (EQ5D-5L): for assessing the generic health status.

Finally, even if no pharmacological treatment or therapeutic strategy were under investigation, patients' respiratory drugs currently assumed were also recorded by pharmacological class.

The primary endpoint was to assess the prevalence of these phenotypes within the Italian COPD population, while the second endpoint was to characterize the multiparametrical picture of each phenotype: both data were still missing in Italy. The preliminary assignment of patients to one of the three phenotypes mentioned above occurred during the single visit at recruitment by reproducing the procedures currently used in everyday clinical practice for defining COPD, such as coupling anamnestic, clinical and instrumental data already available or obtainable during the day of recruitment.

\section{Statistics}

Calculations were carried out on a single population by Full Analysis Set (FAS) that includes all subjects enrolled and who comply with the inclusion and exclusion criteria. Patients who did not fully satisfy entry criteria and/or did not comply with the protocol were excluded from the per-protocol analyses.

The sample size needed for the evaluation of the primary endpoint and able to guarantee the robustness of the emerged estimates was calculated $=384$ patients. The frequency of "phenotypes" was assessed with an accuracy of $\pm 5 \%$ around the central value and a $95 \%$ confidence interval. Given the substantial uncertainty of the frequency of COPD phenotypes still existing in the Italian COPD population, a value of $50 \%$ was assumed in order to avoid any underestimation. The reference formula for the sample size calculation was:

$$
\mathrm{n}=[\mathrm{Np}(1-\mathrm{p})] /[(\mathrm{d} 2 / \mathrm{Z} 21-\alpha / 2 *(\mathrm{~N}-1)+\mathrm{p} *(1-\mathrm{p})]
$$

Moreover, in order to evaluate the possible identifying variables of each phenotype, at least 10 events (namely, subjects belonging to the least frequent phenotype) were needed for each variable (EPV $=10$ ).

Considering a number of independent variables equal to at least 14, the class with lower frequency must be composed of at least 140 subjects. Assuming that the less frequent phenotype represents 10- 
$15 \%$ of the population with COPD, at least 1,000 patients should be enrolled. Continuous variables were expressed as mean and standard deviation (SD), while categorical variables were calculated as absolute number (n) and percentage (\%). ANOVA model or Kruskal-Wallis test were used to compare quantitative variables, while Chi-square test was applied to compare categorical variables. Laboratory data, n. COPD exacerbation, concomitant medications, lung function parameters, and imaging were also analysed and reported in the tables.

As concerning the primary endpoint, the percentage prevalence and the relative Clopper-Pearson confidence interval at 95\% was calculated for each phenotype.

Differences in quantitative variables among the three phenotypes were assessed by the analysis of variance (ANOVA), or by nonparametric Kruskal Wallis test. The Wilcoxon test was used for post-hoc comparisons, while the Bonferroni correction for multiple comparisons.

The association between the phenotypes and the categorical variables were evaluated by the Chi square test. The multinomial logistic regression was used for identifying the variables associated with each phenotype. In the multivariable analysis, the Stepwise selection method was applied considering all variables with a $p \leq 0.1$ in the univariable analysis.

Moreover, the Chi square test was applied to evaluate any difference in MMRC score among the three phenotypes. Relationships between CAT test, EQ5D-5L dimensions and BCS with each phenotype were evaluated by ANOVA, or by the nonparametric Kruskal Wallis test, while the Wilcoxon test was used for post-hoc comparisons, and the Bonferroni correction for multiple comparisons.

For all statistical calculations the software SAS 9.4. was used. A $p<0.05$ was considered statistically significant.

\section{Data quality assurance}

Before the study start, all investigators had been carefully trained during a preliminary investigators' meeting dedicated to the study procedures, and a detailed, specific written manual was delivered to all investigators in order to standardize the terminology. The quality of data was further ensured through the monitoring visits at each site by expert, professional monitors, and by the strict follow up via frequent phone calls.

\section{Ethics}

The study was conducted according to the Good Clinical Practices (GCP), including the archiving of essential documents. In accordance with the Ethical Committee's provisions (study approval on June $\left.15^{\text {th }}, 2017\right)$, the aim of the study was preliminarily clarified to each eligible patient before recruitment, and the patient was then requested to sign his/her informed consent, also for the possible anonymous use of their own data for research purposes.

\section{Results}

A total of 1,012 COPD patients were recruited, and 1,006 of them were valuable. Mean age was 71.5 years $\pm 8.8 \mathrm{SD}$ (min-max: 41-92 years), while the corresponding mean BMI was $27.42 \pm 5.63$ (min-max: 23.6-31.0). Males were $77.0 \%$. Never smokers were $9.1 \%$, while active smokers were $21.2 \%$. COPD severity by GOLD class in the whole sample was: class $1=135 / 1006$; class $2=$ 414/1006; class $3=331 / 1006$, and class $4=126 / 1006$ : the corresponding \% distribution is reported in Figure 1. The COPDCB phenotype was the most prevalent $(48.3 \%, n=486 / 1006 ; 95 \%$ $\mathrm{CI}=45 \%-51 \%)$, followed by the COPD-E phenotype $(38.8 \%$, $\mathrm{n}=391 / 1012 ; 95 \% \mathrm{CI}=63 \%-42 \%)$, and the COPD-A phenotype $(12.8 \%, \mathrm{n}=129 / 1012 ; 95 \% \mathrm{CI}=11 \%-15 \%)$ (Table 1). A fourth phenotype associated to a mix of non-specific prevailing signs was not included in the present study due to its extremely low prevalence $(<0.2 \%)$ (Figure 2$)$. The demographics by phenotype are reported in Table 1: patients belonging to the COPD-A phenotype were slightly younger than those belonging to the other two phenotypes, while no significant differences emerged by gender, height, weight and BMI. The distribution of all independent variables recorded by phenotypes is reported in Table 2. From a general point of view, to note that more than one out of five patients of the whole sample still are current smokers. Moreover, even if around $10 \%$ of never smokers were in the COPD-CB, current smokers and ex-smokers were mostly represented in the COPD-CB and COPD-E phenotypes. Only six patients were reported to be in LTOT or NIV, all of them belonging to the COPD-E phenotype. Dyspnoea as the prevalent respiratory symptom was most frequently reported in patients of the COPD-E phenotype. Conversely, recurrent wheezing was the respiratory sign mostly claimed by patients in the COPD-A phenotype. Furthermore, the frequency of patients claiming $>1$ exacerbations in the previous 12 months was higher in the COPDE phenotype.

In terms of biological variables, both the \% blood eosinophil count (data available in $39.4 \%$ of the sample) and the plasma total IgE levels (data available in the $26.8 \%$ of the sample) had much higher values in the COPD-A phenotype when compared to the other two phenotypes, while $\alpha_{1}$-AT levels $\leq 100 \mathrm{mg} / \mathrm{dl}$ were more frequently found in patients belonging to the COPD-E phenotype.

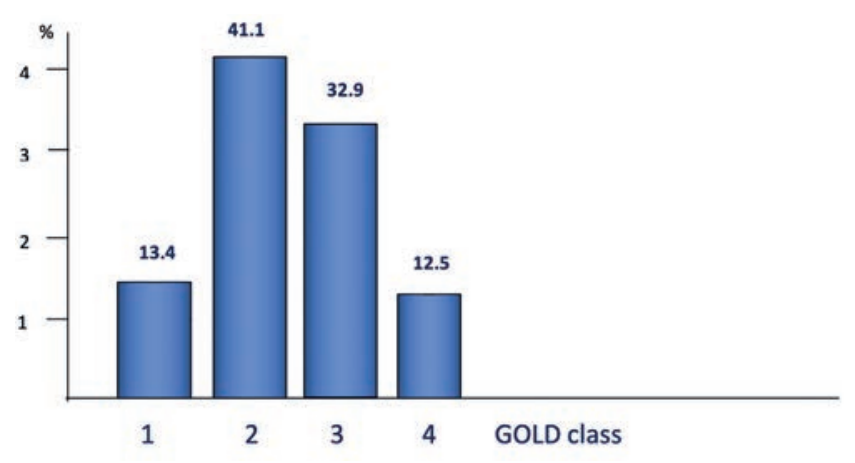

Figure 1. Distribution (\%) of COPD severity by GOLD class $(\mathbf{n}=1006)$.

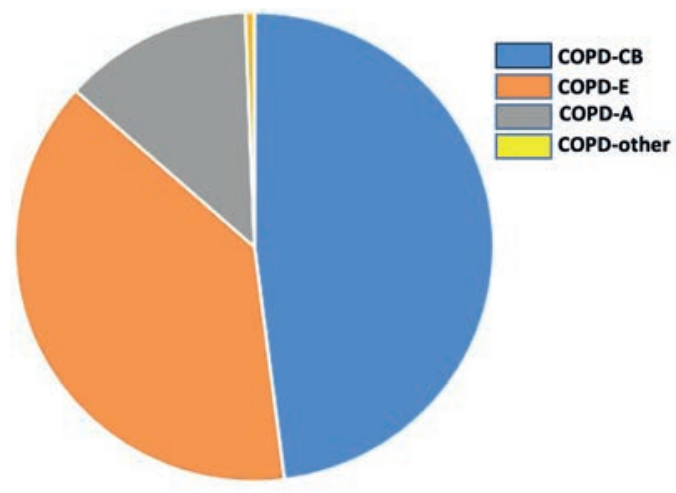

Figure 2. Frequency distribution of phenotypes. 
From a general point of view, lung function was more preserved in the COPD-CB phenotype. In particular, the $\mathrm{FEV}_{1} / \mathrm{VC}$ ratio seemed more sensitive than the corresponding $\mathrm{FEV}_{1} / \mathrm{FVC}$ ratio in grading the severity of current airflow limitation. Moreover, values of RV \% predicted (data available in the $67.7 \%$ of the sample) were higher and those of DLco \% predicted (data available in $54.5 \%$ of the sample) were significantly lower in the COPD-E phenotype. The extent of short-term $\mathrm{FEV}_{1}$ reversibility had the highest mean value in the COPD-A phenotype, while the lowest mean value was found in the COPD-E phenotype. $\mathrm{SpO}_{2}$ was not clearly different within the three phenotypes, except for the COPD-E phenotype.

The explicit mention of emphysema in the chest X-ray reports appeared slightly more frequent in patients of the COPD-E phenotype, even if this difference was not discriminant from that of the other two phenotypes (Table 3). Finally, the distribution of the BODE score indicated that patients of the COPD-CB phenotype were characterized by lower scores more frequently, while higher scores were more frequently observed in the other two phenotypes.

In order to investigate which variables might characterize each phenotype specifically, the COPD-CB phenotype was used as reference. This implies that each result should be interpreted as the probability for a patient with that result of belonging to one of the other two phenotypes, such as the COPD-E or the COPD-A phenotype. All results are reported in Table 3, together with the corresponding level of statistical significancy. As all subjects were COPD patients, cough was not significantly discriminant. Conversely, dyspnoea proved a strong discriminant variable: when dyspnoea was the prevailing symptom claimed, patients had a 3.40 times higher probability to belong to the COPD-E phenotype rather than to the COPD-CB or to the COPD-A phenotype (95\% CI=1.89$6.10 ; p<0.001)$. The role of plasma eosinophils also was highly discriminant. In particular, the probability of belonging to the COPD-A phenotype increased by 2.71 times for any increase of one unit in \% plasma eosinophils ( $95 \% \mathrm{CI}=2.14-3.43$; $<<0.001)$. When compared to the COPD-CB phenotype, smoke; $\mathrm{n}$. exacerbations/year; VR\% predicted, and BODE index proved positively correlated with the COPD-E phenotype, while DLco \% predicted, $\mathrm{SpO}_{2}, \mathrm{FEV}_{1} / \mathrm{VC}$ and $\mathrm{FEV}_{1} / \mathrm{FVC}$ ratio, and short-term $\mathrm{FEV}_{1} \%$ reversibility proved negatively correlated. To note that $\mathrm{FEV}_{1} / \mathrm{VC}$ ratio tended to magnify the extent of airflow limitation

Table 1. Demographics by phenotype.

\begin{tabular}{|c|c|c|c|c|c|}
\hline & Summary statistics & COPD-CB $(n=486)$ & COPD-E (n=391) & COPD-A (n=129) & $\mathbf{p}$ \\
\hline Male & $\%$ & $74.5 \%$ & $80.3 \%$ & $76.7 \%$ & $0.125^{*}$ \\
\hline Age & $\begin{array}{c}\text { Mean } \pm \text { SD } \\
\text { Median (IQR) } \\
\text { Min-max } \\
\text { Min-max }\end{array}$ & $\begin{array}{c}72.1 \pm 8.6 \\
73.0(68-78) \\
41-92 \\
38.0-140.0\end{array}$ & $\begin{array}{c}71.1 \pm 8.9 \\
72.0(65-78) \\
42-91 \\
38.0-120.0\end{array}$ & $\begin{array}{c}70.0 \pm 9.0 \\
71.0(63-77) \\
46-86 \\
38.0-160.0\end{array}$ & $0.033^{* *}$ \\
\hline BMI & $\begin{array}{c}\text { Mean } \pm \text { SD } \\
\text { Median (IQR) } \\
\text { Min-max }\end{array}$ & $\begin{array}{c}27.60 \pm 5.14 \\
27.20(24.0-30.9) \\
16.0-47.9\end{array}$ & $\begin{array}{c}27.00 \pm 5.58 \\
26.60(23.1-30.7) \\
15.6-44.4\end{array}$ & $\begin{array}{c}27.96 \pm 7.28 \\
26.80(23.4-31.8) \\
14.0-62.5\end{array}$ & $0.155^{* * *}$ \\
\hline
\end{tabular}

${ }^{*}$ Chi square; ${ }^{* *}$ non parametric Kruskal Wallis; ${ }^{* * * A N O V A ~ t e s t . ~}$

Table 2. Description of independent variables in the whole sample and by phenotype.

\begin{tabular}{|c|c|c|c|c|c|}
\hline & Summary statistics & COPD-CB $(n=486)$ & COPD-E $(n=391)$ & \multicolumn{2}{|c|}{ COPD-A (n=129) } \\
\hline Never smoking & $\%$ & 11.4 & 6.6 & \multicolumn{2}{|l|}{7.8} \\
\hline Current smoker & $\%$ & 21.3) & 22.3 & \multicolumn{2}{|l|}{17.2} \\
\hline Ex-smoker & $\%$ & 67.3 & 71.1 & \multicolumn{2}{|l|}{75.0} \\
\hline$>1$ exacerbations in the last 12 months & $\%$ & 35.4 & 44.0 & \multicolumn{2}{|l|}{33.6} \\
\hline Dyspnea & $\%$ & 87.9 & 96.1 & \multicolumn{2}{|l|}{86.7} \\
\hline Wheezing & $\%$ & 25.5 & 23.7 & \multicolumn{2}{|l|}{28.9} \\
\hline \% Blood eosinophils & Mean \pm SD & $1.6 \pm 1.4$ & $1.8 \pm 1.5$ & \multicolumn{2}{|l|}{$4.5 \pm 2.4$} \\
\hline Plasma total IgE & Mean \pm SD & $265.6 \pm 484.7$ & $118.5 \pm 232.1$ & \multicolumn{2}{|c|}{$609.4 \pm 1842.9$} \\
\hline$\alpha 1$-AT level $\leq 100 \mathrm{mg} / \mathrm{dl}$ & $\%$ & 2.4 & 4.5 & \multicolumn{2}{|l|}{1.4} \\
\hline $\mathrm{FEV}_{1} \%$ predicted & Mean \pm SD & $73.2 \pm 20.8$ & $45.6 \pm 19.4$ & \multicolumn{2}{|l|}{$55.0 \pm 23.2$} \\
\hline $\mathrm{FEV}_{1} N C, \%$ & Mean \pm SD & $57.9 \pm 20.7$ & $44.6 \pm 19.4$ & \multicolumn{2}{|c|}{$54.6 \pm 19.9$} \\
\hline $\mathrm{FEV}_{1} / \mathrm{FVC}, \%$ & Mean \pm SD & $62.5 \pm 18.1$ & $55.2 \pm 33.1$ & \multicolumn{2}{|l|}{$60.3 \pm 17.1$} \\
\hline $\mathrm{RV}, \%$ predicted & Mean \pm SD & $132.8 \pm 51.3$ & $163.3 \pm 61.9$ & \multicolumn{2}{|c|}{$145.6 \pm 65.2$} \\
\hline FEV1, \% reversibility & Mean \pm SD & $14.5 \pm 14.9$ & $11.1 \pm 10.7$ & \multicolumn{2}{|c|}{$23.5 \pm 18.2$} \\
\hline DLco \% predicted & Mean \pm SD & $66.9 \pm 28.4$ & $45.7 \pm 20.6$ & \multicolumn{2}{|l|}{$72.0 \pm 13.4$} \\
\hline Chest X-ray mentioning emphysema & $\%$ & 25.4 & 31.2 & \multicolumn{2}{|l|}{24.2} \\
\hline $\mathrm{SpO}_{2}, \%$ & Mean \pm SD & $94.9 \pm 4.9$ & $93.4 \pm 5.5$ & \multicolumn{2}{|l|}{$94.7 \pm 2.0$} \\
\hline \multicolumn{6}{|l|}{ BODE index (score) } \\
\hline $0-2$ & $\%$ & & 62.9 & 28.4 & 27.8 \\
\hline $3-4$ & $\%$ & & 26.8 & 34.3 & 30.9 \\
\hline $5-6$ & $\%$ & & 6.4 & 23.5 & 25.8 \\
\hline $7-10$ & $\%$ & & 3.9 & 13.8 & 15.5 \\
\hline
\end{tabular}


when compared to usual $\mathrm{FEV}_{1} / \mathrm{FVC}$, and was more sensitive from this point of view (Table 3). On the other hand, smoke; BODE index; wheezing; \% plasma eosinophils, short-term $\mathrm{FEV}_{1} \%$ reversibility, and DLco \% predicted proved positively correlated with the COPD-A phenotype (Table 3). Finally, the sole mention of "emphysema" in the chest X-ray report did not show any significant relationship with the COPD-E phenotype (Table 3).

The relationships with both total plasma IgE and with alpha- ${ }_{1}$ anti-trypsin $\left(\alpha_{1}\right.$-AT level) plasma levels $\leq 100 \mathrm{mg} / \mathrm{dl}$ were not assessed exactly due to their limited number of recordings. However, data obtained in a limited proportion of patients $(20 \%$ of the whole sample) who provided these data completely tend to support the positive relationship between IgE plasma levels and the COPD-A phenotype, and the higher prevalence of $\alpha 1$-AT levels $<100 \mathrm{mg} / \mathrm{dl}$ in the COPD-E phenotype. The scores of all the Questionnaires used for checking patients' dyspnoea degree, Quality

Table 3. The multinomial logistic regression model $(\mathrm{n}=983)$. Variables significantly related $v$ SOPD-CB are in bold.

\begin{tabular}{|c|c|c|c|c|}
\hline Parameters & Phenotypes* & OR (95\% CI) & Overall p & p \\
\hline $\begin{array}{l}\text { History of smoke } \\
\text { Current smoker vs never } \\
\text { Ex-smoker vs never }\end{array}$ & $\begin{array}{l}\text { COPD-E } \\
\text { COPD-A } \\
\text { COPD-E } \\
\text { COPD-A }\end{array}$ & $\begin{array}{c}1.8(\mathbf{1 . 0}-3.2) \\
1.2(0.5-2.7) \\
\mathbf{1 . 8}(\mathbf{1 . 1 - 3 . 0 )} \\
1.6(0.8-3.3)\end{array}$ & 0.1 & $\begin{array}{c}\mathbf{0 . 0 3 5} \\
0.697 \\
\mathbf{0 . 0 1 8} \\
0.182\end{array}$ \\
\hline $\begin{array}{c}>1 \text { exacerbations/last } 1 \text { yr } \\
\text { Yes us no }\end{array}$ & $\begin{array}{l}\text { COPD-E } \\
\text { COPD-A }\end{array}$ & $\begin{array}{c}1.4(1.1-1.9) \\
0.9(0.6-1.4)\end{array}$ & 0.017 & $\begin{array}{l}\mathbf{0 . 0 1} \\
0.711\end{array}$ \\
\hline $\begin{array}{l}\text { Dyspnea } \\
\text { Yes vs no }\end{array}$ & $\begin{array}{l}\text { COPD-E } \\
\text { COPD-A }\end{array}$ & $\begin{array}{c}\mathbf{3 . 4}(\mathbf{1 . 9 - 6 . 1}) \\
0.9(0.5-1.6)\end{array}$ & $<0.001$ & $\begin{array}{c}<\mathbf{0 . 0 0 1} \\
0.72\end{array}$ \\
\hline $\begin{array}{l}\text { Cough } \\
\text { Yes us no }\end{array}$ & $\begin{array}{l}\text { COPD-E } \\
\text { COPD-A }\end{array}$ & $\begin{array}{c}1.0 \\
0.98(0.6-1.5)\end{array}$ & 0.694 & $\begin{array}{l}0.403 \\
0.922\end{array}$ \\
\hline $\begin{array}{l}\text { Wheezing } \\
\text { Yes vs no }\end{array}$ & $\begin{array}{l}\text { COPD-E } \\
\text { COPD-A }\end{array}$ & $\begin{array}{c}0.9(0.7-1.2) \\
\mathbf{0 . 5}(\mathbf{0 . 3 - 0 . 8})\end{array}$ & 0.043 & $\begin{array}{l}0.537 \\
0.012\end{array}$ \\
\hline $\begin{array}{l}\text { Chest x-ray mentioning em } \\
\text { Yes us no }\end{array}$ & $\begin{array}{l}\text { COPD-E } \\
\text { COPD-A }\end{array}$ & $\begin{array}{l}1.3(0.9-2.1) \\
1.0(0.6-1.8)\end{array}$ & 0.397 & $\begin{array}{l}0.199 \\
0.875\end{array}$ \\
\hline $\mathrm{FEV}_{1} \mathrm{NC} \%$ & $\begin{array}{l}\text { COPD-E } \\
\text { COPD-A }\end{array}$ & $\begin{array}{c}0.97(\mathbf{0 . 9}-\mathbf{1 . 0}) \\
0.99(0.9-1.00)\end{array}$ & $<0.001$ & $\begin{array}{c}<\mathbf{0 . 0 0 1} \\
0.122\end{array}$ \\
\hline $\mathrm{FEV}_{1} / \mathrm{FVC} \%$ & $\begin{array}{l}\text { COPD-E } \\
\text { COPD-A }\end{array}$ & $\begin{array}{c}\mathbf{0 . 9 8}(\mathbf{0 . 9}-\mathbf{1 . 0}) \\
0.99(0.9-1.00)\end{array}$ & $<0.001$ & $\begin{array}{c}<0.001 \\
0.189\end{array}$ \\
\hline RV \% predicted & $\begin{array}{l}\text { COPD-E } \\
\text { COPD-A }\end{array}$ & $\begin{array}{c}1.0(\mathbf{1 . 0}-\mathbf{1 . 0 1}) \\
1.0(1.0-0.1)\end{array}$ & $<0.001$ & $\begin{array}{c}<0.001 \\
0.071\end{array}$ \\
\hline$\% \mathrm{FEV}_{1}$ reversibility & $\begin{array}{l}\text { COPD-E } \\
\text { COPD-A }\end{array}$ & $\begin{array}{l}1.0(1.00-1.3) \\
1.0(0.9-1.0)\end{array}$ & & $\begin{array}{l}0.009 \\
0.015 \\
0.304\end{array}$ \\
\hline DLco \% predicted & $\begin{array}{l}\text { COPD-E } \\
\text { COPD-A }\end{array}$ & $\begin{array}{c}1 \\
1.0(1.00-1.02) \\
1.0(0.9-1.00)\end{array}$ & 0.008 & $\begin{array}{l}0.044 \\
0.059\end{array}$ \\
\hline $\mathrm{SpO}_{2}$ & COPD-E & $\begin{array}{l}1.0 \\
1.0\end{array}$ & 0.07 & 0.024 \\
\hline $\begin{array}{l}\text { BODE index } \\
\qquad \begin{array}{r}3-4 \text { vs } 0-2 \\
5-6 \text { vs } 0-2 \\
\text { 6-10 vs } 0-2\end{array}\end{array}$ & $\begin{array}{l}\text { COPD-E } \\
\text { COPD-A } \\
\text { COPD-E } \\
\text { COPD-A } \\
\text { COPD-E } \\
\text { COPD-A }\end{array}$ & $\begin{array}{l}2.83(1.8-4.5) \\
2.61(1.4-4.8) \\
8.21(4.1-16.3) \\
9.19(4.2-20.2) \\
7.78(3.3-8.1) \\
8.96(3.4-23.2)\end{array}$ & $<0.001$ & $\begin{array}{l}<0.001 \\
<0.002 \\
<0.001 \\
<0.001 \\
<0.001 \\
<0.001\end{array}$ \\
\hline \% Blood eosinophils & $\begin{array}{l}\text { COPD-E } \\
\text { COPD-A }\end{array}$ & $\begin{array}{c}1.1(0.9-1.3) \\
2.7(2.1-3.4)\end{array}$ & $<0.001$ & $\begin{aligned} & 0.28 \\
< & \mathbf{0 . 0 0 1}\end{aligned}$ \\
\hline
\end{tabular}


of Life, and COPD impact showed significant differences by phenotype. In particular, the CAT score allowed to discriminate the COPD-CB from the COPD-E (Wilcoxon test $\mathrm{p}<0.001$ ) and the COPD-A phenotype (Wilcoxon test $\mathrm{p}<0.001$ ) (Table 4). A significant difference within the three phenotypes was also found by the MMRC score (Table 4). When using the BCS, the COPD-E phenotype showed higher scores comparing to those of both COPD-
$\mathrm{CB}$ and of COPD-A phenotypes (Wilcoxon test $\mathrm{p}=0.006$ and $\mathrm{p}<0.001$, respectively) (Table 4 ).

A part the Anxiety/Depression score, all the other sub-scores of the EQ5d-5L questionnaire showed a lower impact in the COPD$\mathrm{CB}$ than in the COPD-E phenotype, particularly as concerning the Mobility, the Self Care, the Usual activities, and the VAS scores (Table 5). Finally, the prevalence of current therapeutic treatments

Table 4. CAT, BCS, and MRC questionnaires by phenotype.

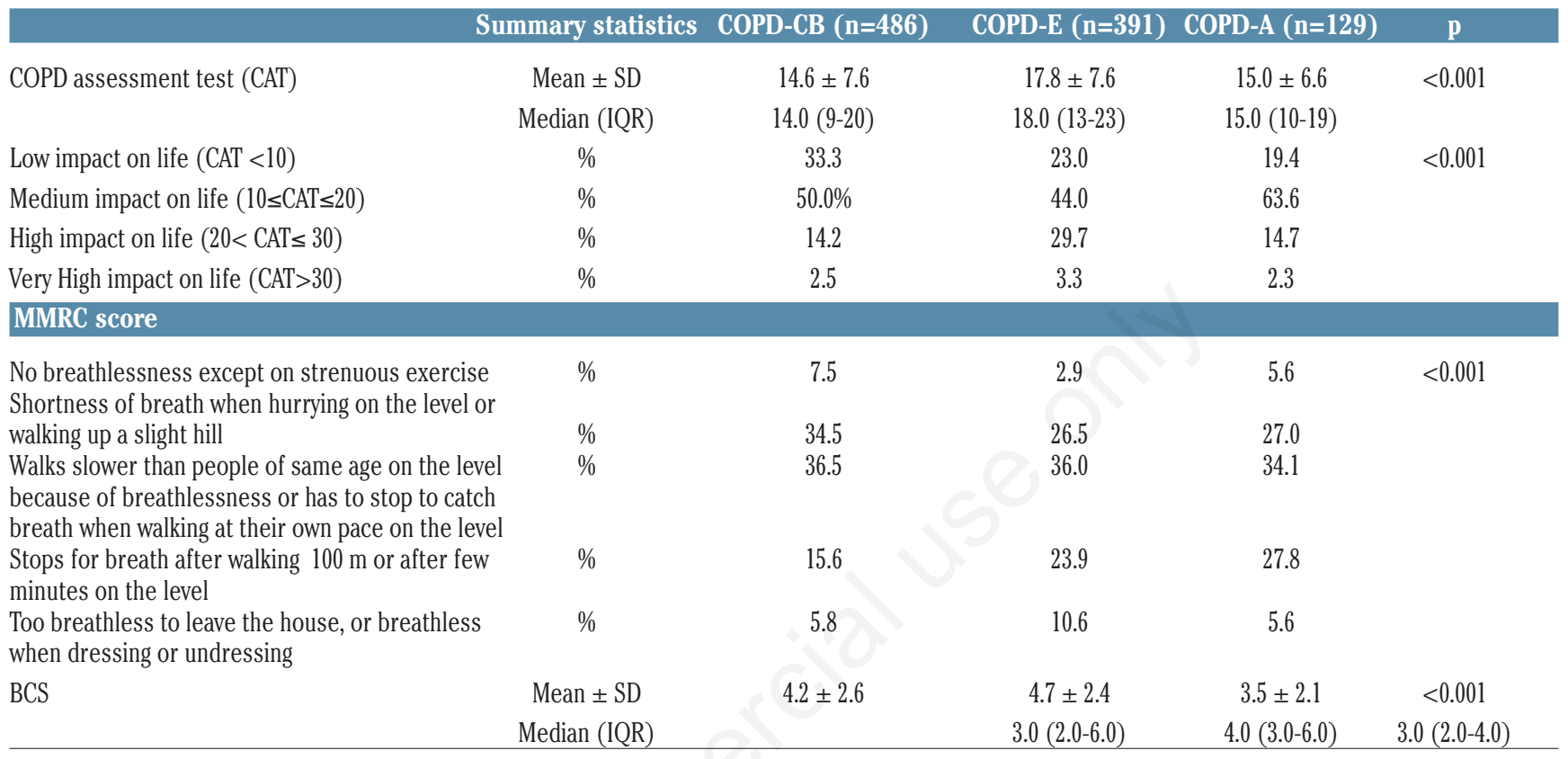

Table 5. The EQ5d-5L questionnaire scores by phenotype.

\begin{tabular}{|c|c|c|c|c|c|}
\hline & & COPD-CB $(n=486)$ & COPD-E (n=391) & COPD-A (n=129) & p \\
\hline $\begin{array}{l}\text { EQ-5D-5L questionnaire mobility } \\
\qquad \begin{array}{l}2 \\
3 \\
4-5\end{array}\end{array}$ & $\begin{array}{c}\text { Mean } \pm \text { SD } \\
\text { Median (IQR) } \\
\% \\
\% \\
\%\end{array}$ & $\begin{array}{c}1.9 \pm 0.9 \\
2.0(1.0-3.0) \\
73.8 \\
20.8 \\
5.5\end{array}$ & $\begin{array}{c}2.2 \pm 1.0 \\
2.0(1.0-3.0) \\
59.0 \\
28.8 \\
12.2\end{array}$ & $\begin{array}{c}2.0 \pm 0.9 \\
2.0(1.0-3.0) \\
68.5 \\
27.9 \\
3.6\end{array}$ & $<0.001$ \\
\hline $\begin{array}{l}\text { Self-care } \\
\text { Median (IQR) } \\
\quad 1-2 \\
3 \\
4-5\end{array}$ & $\begin{array}{c}\text { Mean } \pm \text { SD } \\
1.0(1-2) \\
\% \\
\% \\
\%\end{array}$ & $\begin{array}{c}1.5 \pm 0.8 \\
2.0(1-2) \\
85.8 \\
11.5 \\
2.7\end{array}$ & $\begin{array}{c}1.8 \pm 1.0 \\
2.0(1-2) \\
78.3 \\
14.2 \\
7.5\end{array}$ & $\begin{array}{c}1.8 \pm 0.9 \\
77.5 \\
18.9 \\
3.6\end{array}$ & $<0.001$ \\
\hline $\begin{array}{l}\text { Usual activities } \\
\text { Median (IQR) } \\
1-2 \\
3 \\
4-5\end{array}$ & $\begin{array}{c}\text { Mean } \pm \text { SD } \\
2.0(1.0-2.0) \\
\% \\
\% \\
\%\end{array}$ & $\begin{array}{c}1.8 \pm 0.9 \\
2.0(1.0-3.0) \\
78.1 \\
16.9 \\
4.9\end{array}$ & $\begin{array}{c}2.1 \pm 1.0 \\
2.0(1.0-3.0) \\
67.8 \\
21.7 \\
10.5\end{array}$ & $\begin{array}{c}2.1 \pm 0.9 \\
66.7 \\
27.9 \\
5.4\end{array}$ & $<0.001$ \\
\hline $\begin{array}{l}\text { Pain/discomfort } \\
\quad \text { Median (IQR) } \\
1-2 \\
3 \\
4-5\end{array}$ & $\begin{array}{c}\text { Mean } \pm \text { SD } \\
2.01 .0-2.0) \\
\%, \\
\%, \\
\%,\end{array}$ & $\begin{array}{c}1.8 \pm 0.9 \\
1.0(1.0-2.0) \\
78.4 \\
17.8 \\
3.8 \\
\end{array}$ & $\begin{array}{c}1.7 \pm 0.9 \\
1.0(1.0-2.0) \\
79.3 \\
18.0 \\
2.7\end{array}$ & $\begin{array}{c}1.7 \pm 0.9 \\
81.1 \\
15.3 \\
3.6\end{array}$ & 0.049 \\
\hline $\begin{array}{l}\text { Anxiety/depression } \\
\quad \text { Median (IQR) } \\
\quad 1-2 \\
3 \\
\quad 4-5\end{array}$ & $\begin{array}{c}\text { Mean } \pm \text { SD } \\
2.0(1.0-2.0) \\
\% \\
\% \\
\%\end{array}$ & $\begin{array}{c}1.8 \pm 0.9 \\
2.0(1.0-2.0) \\
80.9 \% \\
14.5 \\
4.6\end{array}$ & $\begin{array}{c}1.8 \pm 0.91 \\
1.0(1.0-2.0) \\
78.6 \\
16.9 \\
4.4\end{array}$ & $\begin{array}{c}1.7 \pm 0.89 \\
82.0 \\
13.5 \\
4.5\end{array}$ & 0.795 \\
\hline $\begin{array}{l}\text { VAS score } \\
\quad \text { Median (IQR) }\end{array}$ & $\begin{array}{c}\text { Mean } \pm \text { SD } \\
65.0(50.0-78.0)\end{array}$ & $\begin{array}{c}63.2 \pm 19.0 \\
60.0(50.0-70.0)\end{array}$ & $\begin{array}{c}58.5 \pm 17.5 \\
60.0(50.0-70.0)\end{array}$ & $60.6 \pm 17.8$ & $<0.001$ \\
\hline
\end{tabular}


recorded by phenotype are reported in Table 6. Bronchodilators were currently assumed alone or in combination (such as: adrenergics, anticholinergics, or adrenergics+anticholinergics) by $76.7 \%$ of COPD-E patients, by $63.5 \%$ of COPD-CB, and by $67.4 \%$ COPD-A patients, respectively. Conversely, ICS in combination with bronchodilators were assumed by $34.1 \%$ of COPD-A patients, by $32.0 \%$ of COPD-E patients, and by $27.2 \%$ of COPD-CB patients. The association of adrenergics+anticholinergics+ICS was mostly assumed by COPD-E patients. As expected, NIV and oxygen were peculiarly more frequently used in the COPD-E phenotype, while their lowest use was observed in the COPD-CB phenotype.

\section{Discussion}

COPD is a complex and progressive respiratory condition characterized by clinical presentations that are multifaceted and highly heterogeneous in real life [1,5-8]. Actually, there is a consolidate evidence that what is currently defined "COPD" corresponds to various respiratory conditions that can be variably characterized in clinical, biological, and lung function terms: such as, the different phenotypes of COPD $[11,15,25]$. Several COPD phenotypes have been progressively identified in the literature $[11,24]$, even if only a few of them are those most frequently encountered in daily clinical activity $[10,12,14,26]$. Their identification would be of great clinical value because they can substantially affect the therapeutic strategy, the short- and long-term outcomes, and the overall impact of COPD.

Even if recommended [12], the prevalence and the multiparametrical characterization of the COPD phenotypes had never been previously assessed in Italy on representative samples of COPD population. Nor it was done by using those variables that are currently available in real-world medical practice.

From the CLIMA study, the picture of each phenotype should emerge as consisting of a composite mix of parameters deriving from the patients' history, a few specific biological data, and some lung function parameters: all easy to collect, but characterized by a high discriminating power, statistically validated. Actually, only a small proportion of the variables considered for the study proved sensitive enough to fit the aim of the investigation, and are then worthy of comments and comparison to the specific literature available.

In concordance with previous studies [10,12,14,26], three were the most frequent COPD phenotypes recognized also in the present study: i) one, mainly related to the picture of chronic bronchitis; i) another, presumably characterized by the presence of emphysema at variable extent; ii) the last one, characterized by a picture of COPD mixed to bronchial asthma. In particular, the COPD-CB phenotype confirmed as the most frequent in clinical practice, while the most frequent exacerbators were patients belonging to the COPD-E phenotype, who also showed the poorest lung function profile, the lowest quality of life, and the highest impact on health status. These data compared by phenotype correspond very well to those of other recent studies carried out in Central-Eastern Europe and in Far East regions and showing that the majority of COPD patients have a prevailing chronic bronchitis picture characterized by lower rates of exacerbations when compared to those of other phenotypes [27,28].

From a general point of view, to keep in mind that the patient's smoke habit is still worthy of a systematic check in clinical practice as the condition of current and of former-smoker once again proved significantly related to the presence of some emphysema component of COPD, with higher probability. However, it should also be noted that $6-11 \%$ of the whole sample were patients who never smoked even if suffering from COPD: this evidence further suggests the substantial role of other underlying determinants of COPD in these cases (i.e., environmental or occupational risks; recurrent infections, etc.). Moreover, differently from other Countries where females already equaled the males' prevalence of COPD and also that of smoke attitude (29), the present study showed that the gender dependance of COPD still is dramatically in favor of males in Italy, regardless the phenotype they belong to.

As concerning the specific discriminating power of the prevailing respiratoty symptoms spontaneously claimed (namely cough, dyspnoea, wheezing), the role of cough was negligible indeed in discriminating the three phenotypes: this evidence was expected when considering that all patients included had chronic cough as their basic common symptom. Conversely, the occurrence of dyspnoea as the prevailing symptom, rather than wheezing, contributed significantly in identifying the COPD-E rather than the COPD-CB the COPD-A phenotype. In other words, the message to retain for the daily practice is that, when representing the prevailing symptom, dyspnoea tends to support the existence of a substantial emphysema component of COPD peculiarly, while the recurrence of wheezing more likely tends to suggest the concomitant role of asthma components.

In concordance with several previous controlled studies [3032], the role of blood eosinophil count in discriminating the asthma component of COPD results further highlighted also in the present study where it proved sensitive indeed. This evidence is of crucial clinical value as the eosinophil count, that is a very simple and quick parameter to obtain at low cost, represents a quite relevant indicator for choosing the most appropriate therapeutic regimen. Unfortunately, the exact relationships between other two endotypes (namely, high IgE expression and $\alpha 1-A T$ deficiency) to each COPD phenotype were impossible to assess exactly in the present study due to the too high number of missings. However, data obtained in the limited proportion of patients who provided these data completely tend to support the positive relationship between $\operatorname{IgE}$ plasma levels and the COPD-A phenotype, and the higher prevalence of $\alpha 1$-AT levels $<100 \mathrm{mg} / \mathrm{dl}$ in the COPD-E phenotype. To pinpoint that other studies found the same trends in comparable

Table 6. Distribution of current treatments by phenotype.

\begin{tabular}{lcccc} 
& & COPD-CB $(\mathbf{n = 4 8 6})$ & COPD-E $(\mathbf{n = 3 9 1})$ & COPD-A (n=129) \\
Adrenergics & $\%$ & 6.0 & 9.2 & 5.4 \\
Anticholinergics & $\%$ & 27.4 & 35.3 & 37.2 \\
\hline Adrenergics+Anticholinergics & $\%$ & 30.5 & 32.2 & 24.8 \\
Adrenergics+ICS & $\%$ & 27.0 & 31.2 & 34.1 \\
\hline Adrenergics + Anticholinergics + ICS & $\%$ & 0.2 & 0.8 & 0.0 \\
NIV and/or oxygen & $\%$, & 4.1 & 14.3 & 10.1 \\
\hline
\end{tabular}


samples of COPD subjects [33,34].

A further crucial issue is the identification of the peculiar lung function profile for each one of the phenotypes investigated in clinical practice. This critical issue is still debated since long ago and it had been investigated from this point of view in different countries $[35,36]$, although so far not in Italy. The main message currently emerging from the literature is that the spirometric staging only based on a sole parameter (usually the $\mathrm{FEV}_{1}$ ) is not sensitive enough for describing the complexity and the heterogeneity of the COPD and to characterize the patients' profile of its different phenotypes $[8,9,37,38]$. Actually, $\mathrm{FEV}_{1}$ reflects all the different determinants underlying COPD airflow limitation globally, and is not specific enough for mirroring each airway or parenchymal pathogenetic mechanism contributing to different COPD phenotypes [13]. The $\mathrm{FEV}_{1} / \mathrm{FVC}$ ratio remains the diagnostic criterion for persistent airflow limitation even if it is known to only partially correlate with the disease impact on patients' symptoms [39]. The $\mathrm{FEV}_{1} / \mathrm{VC}$ ratio (a measure also simple to obtain, but where $\mathrm{VC}$ is more related to the elastic recoil) proved more sensitive from this point of view $[40,41]$. Again, the higher sensitivity of the $\mathrm{FEV}_{1} / \mathrm{VC}$ ratio should also be expected when realizing that $\mathrm{FEV}_{1} / \mathrm{FVC}$ represents the ratio between two forced volumes, while $\mathrm{FEV}_{1} / \mathrm{VC}$ is the ratio between a forced to a resting volume, thus resulting the extent of the current flow limitation magnified.

In general, the occurrence of a significant short-term $\mathrm{FEV}_{1}$ reversibility confirmed of limited value for distinguishing the COPD phenotypes, even if the $\mathrm{FEV}_{1} \%$ recover $\geq 12 \%$ and of $200 \mathrm{ml}$ from basal values was more frequently observed in COPD patients characterized by active asthma components rather than in those with emphysema components, ranging $11-23 \%$ respectively. These results are very similar to those found in a recent study aimed to assess the bronchodilator reversibility in a large sample of more than 35,000 patients obtained by combining three large population studies (ranging 17.3-18.4\%), even if these studies were not carried out with the principal aim of comparing different phenotypes of COPD [42].

Just in order to proceed beyond $\mathrm{FEV}_{1}$, the measure of DLco confirmed to be probative indeed in favor of the COPD-E phenotype, and data obtained in the CLIMA study are absolutely comparable to those of a similar study of only a few years ago [43]. Actually, in concordance with lung physiology, the existence of a substantial damage of alveolar membrane and peripheral deranged distribution of ventilation can be suggested in those patients with high probability. This evidence is of particular relevance when compared to the negligible discriminant value of the generic and too frequently recurring mention of "emphysema" recorded in the chest $\mathrm{x}$-ray reports of these patients. It is very likely that this bias may happen due to possible inappropriateness occurring in radiological procedures, or in x-ray reporting. Unfortunately, the use of DLco measures still is infrequent in Italy for current clinical purposes, likely due to the need of equipments more complex, expensive and requiring skilled users than the simple spirometry.

Data provided by multiparametrical scores were of great interest, too. In particular, the BODE score (which consists per sé of BMI, $\mathrm{FEV}_{1}$, dyspnea, 6 minutes walking test) [44] had a significant role in phenotyping COPD patients of the present study: actually, COPD-CB patients were characterized by much lower BODE scores with high frequency, while the severe BODE scores were much more frequently recorded in patients of both the COPD$\mathrm{E}$ and COPD-A phenotypes, thus suggesting a much higher structural involvement of airway and lung structures in these cases. The Questionnaires used in the present study for checking any difference in Quality of Life, health status and impact for each COPD phenotype confirmed their significant high sensitivity in discriminating peculiarly the COPD-E from the other phenotypes investigated. In other words, the existence of some emphysema components can be quickly supposed by these questionnaires that can be easily filled by patients while waiting for the precise biological and lung function definition of their COPD [45].

Finally, even if, in general terms, the most treated patients were those belonging to the COPD-E and COPD-A phenotypes, the therapeutic attitude emerged from the present study reflects once again that a substantial proportion of COPD patients were not receiving the appropriate treatment in Italy [46], and tends to underline the still too poor recognition of at least the most common COPD phenotypes.

The study has some limitations. Points of weakness are: due to logistical and time requirements, data collection was carried out only during the sole recruitment visit. Some biological data were only available in a limited proportion of patients and their precise relationships with each phenotype, even if suggestive to be highly probable, were impossible to calculate exactly. Moreover, some lung function parameters and questionnaires were also not available in all patients, even if their number was largely sufficient for regressions in this case (redemption always ranging $54^{3} 90 \%$ ). Unfortunately, bronchial hyper-reactivity had been performed in a too limited number of patients $(<20 \%)$. No arterial blood gas data were available because the design of the study privileged its feasibility by avoiding invasive (arterial) measures. Point of strength are: the consistency of the sample and the even distribution throughout Italy of the specialist sites contributing to the study. Finally, the multiparametrical and probabilistic approach to the tentative characterization of COPD phenotypes.

\section{Conclusions}

COPD is a complex, multifaceted chronic disorder that can be declined by different phenotypes. Currently, their recognition is still not sufficiently pursued and their operational value still insufficiently valued in current clinical practice, thus perpetuating the already blurred vision of COPD. However, the prevailing determinants of COPD may be highlightable by some usual parameters, easy to obtain. Otherwise, when diagnosing COPD, even if unaware, clinicians are tilting between the Dutch and the British pathogenetic hypothesis $[47,48]$, with poorer results than expected. In general, the identification of peculiar lung function profiles framing the most frequent COPD phenotypes is achievable in short time and at low cost also in clinical practice. Of course, the parameters should be rightly chosen, used timely, and interpreted effectively. The use of specific questionnaires for assessing Quality of Life, health status and impact can also provide a further quick support for discriminating the main phenotypes of COPD in short time. Stemming from this bulk of evidence, it should be emphasized that the phenotypical approach to COPD would be of greatly impact. Actually, the disease management would be much more appropriate and effective, and the therapeutic strategy more targeted and fitting with the dictates of precision medicine $[21,49,50]$ also in everyday clinical practice.

\section{Acknowledgments}

Authors are very grateful to Dr. Valentina Panetta who performed all statistical analyses. Authors also are grateful to A. Menarini I.F.R. for the unrestricted grant in support of the CLIMA Study, and of the paper publication. 


\author{
Abbreviations \\ BCS: Borg Category scale \\ BMI: Body mass index \\ BODE index: BMI, obstruction, dyspnea and exercise performance \\ index \\ CAT: COPD assessment test \\ COPD: Chronic obstructive pulmonary disease \\ DLCO: Diffusing capacity \\ EQ5D-5L: Quality of life questionnaire 5-level \\ FVC: Forced vital capacity \\ $\mathrm{FEV}_{1}$ : Forced expiratory volume in 1 second \\ GCP: Good clinical practice \\ GP: General practitioner \\ IgE: Immunoglobulines E \\ mMRC: Modified Questionnaire of British Medical Research \\ Council \\ 6MWT: Six minute walking test \\ RV: Residual volume \\ $\mathrm{SpO}_{2}$ : Oxygen \% saturation \\ VC: Vital capacity \\ a1-AT: alpha1 anti-trypsin
}

*The CLIMA Study Group:

R.W. Dal Negro, Centro Nazionale Studi di Farmacoeconomia e Farmacoepidemiologia Respiratoria, Verona; M. Carone, Fondazione S. Maugeri, Cassano delle Murge (BA); G. Cuttitta, IBIM-CNR, Palermo; L. Gallelli, Azienda Ospedaliera Universitaria Mater Domini, U.O. Farmacologia, Catanzaro; M. Pistolesi, Azienda Ospedaliera Universitaria Careggi - Pneumologia e Fisiopatologia Toraco-Polmonare, Firenze; S. Privitera, C.P.M., Giarre, Catania; P. Ceriana IRCCS Fondazione Salvatore Maugeri, Clinica del Lavoro e della Riabilitazione, Pavia; P. Pirina U.O. di Pneumologia, Azienda Ospedaliera Universitaria, Sassari; B. Balbi Unità Operativa di Pneumologia Riabilitativa Istituto Scientifico, Veruno, Novara; C. Vancheri, Pneumologia Riabilitativa, Azienda Ospedaliera Universitaria Policlinico, Vittorio Emanuele, Catania; F.M. Gallo, SSD Pneumologia Territoriale, Azienda Sanitaria Locale, Matera; A. Chetta, Clinica Pneumologica, Azienda Ospedaliera Universitaria-Ospedale G. Rasori, Parma; S. Baglioni, S.C. Pneumologia, Azienda Ospdealiera, Perugia; C. Bucca, AOU Molinette, SCDU Pneumologia, Torino; F. Mazza, S.C. Pneumologia, Azienda per l'Assistenza Sanitaria n. 5, Friuli Occidentale, Pordenone; A. Melani, Policlinico S. Maria alle Scotte, Ambulatorio Fisiopatologia Respiratoria, Siena; A. Sanna, U.O. di Pneumologia, Ospedale Civile, Pistoia; M. Latorre, Presidio Ospedaliero delle Apuane. U.O. Pneumologica, MassaCarrara; C. Micheletto, Azienda U.L.S.S. n. 21, UOC di Pneumologia, Legnago (VR); S. Marinari, Ospedale Policlinico SS. Annunziata, Divisione di Pneumologia, Chieti; F. De Blasio, Casa di Cura Clinic Center, Pneumologia, Napoli; S. Bellofiore, Presidio Ospedaliero A.O.U., Policlinico Vittorio Emanuele di Catania, Chirurgia Toracica Padiglione M1, Catania; P. Turco Research \& Clinical Governance, Verona, Italy.

\section{References}

1. Fletcher CM, Peto R. The natural history of chronic airflow obstruction. Br Med J 1977;1:1645-8.

2. Mannino DM, Higuchi K, Yu TC, Zhou H, Li Y, Tian H, et al. Economic burden of chronic obstructive pulmonary disease by presence of comorbidities. Chest 2015;147:199-201.
3. Dal Negro RW, Celli BR. Patient Related Outcomes-BODE (PRO-BODE): A composite index incorporating health utilization resources predicts mortality and economic cost of COPD in real life. Respir Med 2017;131:175-8

4. Dal Negro RW. COPD: The annual cost-of-illness during the last two decades in Italy, and its mortality predictivity power. Healthcare 2019;7:35.

5. Snider GL. Chronic obstructive pulmonary disease: A definition and implications of structural determinants of airflow obstruction for epidemiology. Am Rev Respir Dis 1989;140:S38.

6. Fabbri LM, Romagnoli M, Corbetta L, Casoni G, Busljetic K, Turato G, et al. Differences in airway inflammation in patients with fixed airflow obstruction due to asthma or chronic obstructive pulmonary disease. Am J Respir Crit Care Med 2003;167:418-24.

7. Hogg JC, Chu F, Utokaparch S, Woods R, Elliott WM, Buzatu $\mathrm{L}$, et al. The nature of small-airway obstruction in chronic obstructive pulmonary disease. N Engl J Med 2004;350:264553.

8. Han MK, Agusti A, Calverly PM, Celli BR, Criner G, Curtis JL, et al. Chronic obstructive pulmonary disease phenotypes: the future of COPD. Am J Respir Crit Care Med 2010;182:598604.

9. Global initiative for Chronic Obstructive ILung Disease. Global strategy for the diagnosis, management, and prevention of chronic obstructive pulmonary disease. Accessed: March 30, 2015. Available from: http://www.goldcopd.org/uploads/ users/files/GOLD_Report_2015_feb18.pdf

10. Soriano JB, Davis KJ, Coleman $\bar{B}$, Visick G, Mannino D, Pride NB. The proportional Venn diagram of obstructive lung disease: Two approximations from the United States and the United Kingdom. Chest 2003;124:474-81.

11. Marsh SE, Travers J, Weatherall M, Williams MV, Aldington S, Shirtcliffe PM, et al. Proportional classifications of COPD phenotypes. Thorax 2008;63:761-7.

12. Segreti A, Stirpe E, Rogliani P, Cazzola M. Defining phenotypes in COPD: an aid to personalized healthcare. Mol Diagn Ther 2014; 18:381-8.

13. Sheikh K, O Coxon H, Parraga G. This is what COPD looks like. Respirology 2016;21:224-36.

14. Rogliani P, Ora J, Puxxeddu E, Cazzola M. Airflow obstruction: is it asthma or is it COPD? Int J Chron Obstruct Pulmon Dis 2016;11:3007-13.

15. Calle Rubio M, Casamor R, Miravitlles M. Identification and distribution of COPD phenotypes in clinical practice according to Spanish COPD Guidelines: The FENEPOC study. Int J Chron Obstruct Pulmon Dis 2017;9;12:2373-83.

16. Beeh KM, Kornmann O, Beier J, Ksoll M, Buhl R. Clinical application of a simple questionnaire for the differentiation of asthma and chronic obstructive pulmonary disease. Respir Med 2004;98:591-7.

17. Gibson PG, Simpson JL. The overlap syndrome of asthma and COPD: What are its features and how important is it? Thorax 2009;64:728-35.

18. Zeki AA, Schivo M, Chan A, Albertson TE, Louie S. The asthma-COPD overlap syndrome: A common clinical problem in the elderly. J Allergy 2011;2011:861926.

19. Sobradillo P, Garcia-Aymerich J, Agusti A. Clinical phenotypes of COPD. Arch Bronchopneumol 2010;46:s8-11.

20. Vestbo J. COPD: definition and phenotypes. Clin Chest Med 2014;35:1-6.

21. Polverino F, Sam A, Guerra S. COPD: to be or not to be, that is the question. Am J Med 2019;132:1271-8. 
22. Fragoso E, André S, Boleo-Tomè JP, Arelas V, Munha J, Cardoso J. Understanding COPD: a vision on phenotypes, comorbidities and treatment approach. Rev Port Pneumol 2016;22:101-11.

23. Siafakas N, Corlateanu A, Fouka E. Phenotyping before starting treatment in COPD? COPD 2017; 14:367-74.

24. Segal LN, Martinez FJ. Chronic obstructive pulmonary disease subpopulations and phenotyping. J Allergy Clin Immunol 2018;141:1961-71.

25. Snider GL. What's in a name? Names, definitions, descriptions, and diagnostic criteria of diseases, with emphasis on chronic obstructive pulmonary disease. Respiration 1995;62:297-301.

26. Pinto LM, Alghamdi M, Benedetti A, Zaihara T, Landry T, Bourbeau J. Derivation and validation of clinical phenotypes for COPD: a systematic review. Respir Res 2015;16:50.

27. Koblikek V, Milienkovic B, Barczyk A, Tkacova R, Somfay A, Zykov K, et al. Phenotypes of COPD patients with a smoking history in Central and Eastern Europe: the POPE Study. Eur Respir J 2017;49:1601446.

28. Ciai CS, Liam CK, Pang YK, Ng DLC, Tan SB, Wong TS, Sia JE. Clinical phenotypes of COPD and health related quality of life: a cross sectional study. Int J Chron Obstruct Pulmon Dis 2019; $14: 565-73$.

29. Gut-Gobert C, Cavailles A, Dixmier A, Guiollot S, Joneau S, Leroyer $\mathrm{C}$, et al. Women and COPD: do we need more evidence? Eur Respir Rev 2019;28:180055.

30. Green RH, Brightling CE, Bradding P. The reclassification of asthma based on subphenotype. Curr Opin Allergy Clin Immunol 2007;7:43-50.

31. Putcha N, Fawzy A, Matsui EC, Liu MC, Bowler RP, Woodruff PG, et al. Clinical phenotypes of atopy and asthma in COPD: A meta-analysis of SPIROMICS and COPD gene. Chest 2020;158:2333-45.

32. Hurst JR, Vestbo J, Anzueto A, Locantore N, Müllerova H, TalSinger R, et al. Susceptibility to exacerbation in chronic obstructive pulmonary disease. N Engl J Med 2010;363:112838.

33. Skold CM. Remodeling in asthma and COPD - differences and similarities. Clin Respir J 2010;4:s20-7.

34. Singh D, Kolsum U, Brightling CE, Locantore N, Agusti A, TalSinger R, et al. Eosinophilic inflammation in COPD: prevalence and clinical characteristics. Eur Respir J 2014;44:1697-700.

35. No authors listed. Standards for the diagnosis and care of patients with chronic obstructive pulmonary disease. Am J Respir Crit Care Med 1995;152:S77-121.

36. Miravitlles M, Calle M, Soler-Cataluña JJ. Clinical phenotypes of COPD: identification, definition and implications for guidelines. Arch Bronconeumol 2012;48:86-98.

37. Macklem PT, Mead J. Resistance of central and peripheral airways measured by a retrograde catheter. J Appl Physiol 1967;22:395-401

38. Lange P, Halpin DM, O'Connell DE, MacNee W. Diagnosis, assessment, and phenotyping of COPD beyond FEV1. Int $\mathrm{J}$ Chron Obstruct Pulmon Dis 2016;11 3-12.

39. Jones PW. Health status measurement in chronic obstructive pulmonary disease. Thorax 2001;56:880-7.

40. Sciurba FC. Physiological similaritiesand differencs between COPD and asthma. Chest 2004;126:117s-24.

41. Puente-Maestu L, Stringer WW. Hyperinflation and its management in COPD. Int $\mathrm{J}$ Chron Obstruct Pulmon Dis 2006;1:381-400.

42. Janson C, Malinovschi A, Amaral AFS, Accordini S, Bousquet $\mathrm{J}$, Buist AS, et al. Bronchodilator reversibility in asthma and COPD: findings from three large population studies. Eur Respir J 2019;54:1900561

43. Vazquez JH, Garcia IA, Meca AA, de Andres AL, Ruix CM, Garcia MJB, et al. COPD phenotypes: differences in survival. Int J Chron Obstruct Pulmon Dis 2018;13:2245-51.

44. Celli BR, Cote CG, Marin JM, Casanova C, Montes de Oca M, Mendez RA, et al. The body-mass index, airflow obstruction, dyspnea, and exercise capacity index in chronic obstructive pulmonary disease. N Engl J Med 2004;350:1005-12.

45. Jones PW, Brusselle G, Dal Negro RW, Ferrer M, Kardos P, Levy ML, et al. Health-related quality of life in patients by COPD severity within primary care in Europe. Respir Med 2011;105: 57-66.

46. Dal Negro RW, Bonadiman L, Turco P, Tognella S, Iannazzo S. Costs of illness analysis in Italian patients with chronic obstructive pulmonary disease (COPD): an update. Clinicoecon Outcomes Res 2015;7:153-9

47. Barnes PJ. Against the Dutch hypothesis: asthma and chronic obstructive pulmonary disease are distinct diseases. Am J Respir Crit Care Med 2006;174:240-4. 2.

48. Kraft M. Asthma and chronic obstructive pulmonary disease exhibit common origins in any country. Am J Respir Crit Care Med 2006;174:238-40

49. Corlateanu A, Mendez Y, Wang Y, de Jesus Avendano Garnica R, Botnaru V, Siafakas N. Chronic obstructive pulmonary disease and phenotypes: a state-of-the-art. Pulmonology 2020; 26: $95-100$

50. Milanese M, Viegi G, Sposato B, Dal Negro RW. Respiratory function testing in the era of precision medicine. Clin Respir Med 2020;2:1009.

Received for publication: 4 June 2021. Accepted for publication: 16 July 2021.

This work is licensed under a Creative Commons Attribution-NonCommercial 4.0 International License (CC BY-NC 4.0).

CC Copyright: the Author(s), 2021

Licensee PAGEPress, Italy

Multidisciplinary Respiratory Medicine 2021; $16: 790$

doi:10.4081/mrm.2021.790 